\title{
Global variation in marine fish body size and its role in biodiversity-ecosystem functioning
}

\author{
Jonathan A. D. Fisher ${ }^{1,2, *}$, Kenneth T. Frank ${ }^{2}$, William C. Leggett ${ }^{1}$ \\ ${ }^{1}$ Department of Biology, Queen's University, Kingston, Ontario K7L 3N6, Canada \\ ${ }^{2}$ Ocean Sciences Division, Bedford Institute of Oceanography, PO Box 1006, Dartmouth, Nova Scotia B2Y 4A2, Canada
}

\begin{abstract}
To date, investigations of the positive relationships between biodiversity and ecosystem functioning among global marine ecosystems, and the management initiatives derived from these studies, have focused exclusively on species richness. We hypothesize that body size variations that occur among size-structured aquatic ecosystems subjected to exploitation may also contribute to these patterns. Our analyses of maximum lengths of 12151 fish species from 56 exploited large marine ecosystems (LMEs) revealed a 2-fold variation in geometric mean lengths, that were strongly and negatively correlated with species richness. LMEs characterized by larger mean sizes were also skewed towards dominance by large species. The expected positive and significant correlation between mean fish length and latitude (characterized as Bergmann's Rule) was observed among North Atlantic, South Pacific, and Indian Ocean (southern latitudes) LMEs, but not in 3 other regions, including the North Pacific. In the North Atlantic, anomalous longterm declines in top predator catch rates (one measure of ecosystem functioning) occurred, and within temperate North Atlantic LMEs, species size distributions were more skewed towards large species relative to North Pacific LMEs. Our global analyses indicate that fish body size may act as a factor of considerable importance in mediating the relationship between global marine fish species richness and ecosystem functioning, and that management initiatives to ensure ecosystem stability in the face of exploitation should include the restoration and maintenance of this important functional trait.
\end{abstract}

KEY WORDS: Biogeography · Bergmann's Rule · Overexploitation · Fisheries · Macroecology $\cdot$ Species richness $\cdot$ Temperate $\cdot$ Tropical

Resale or republication not permitted without written consent of the publisher

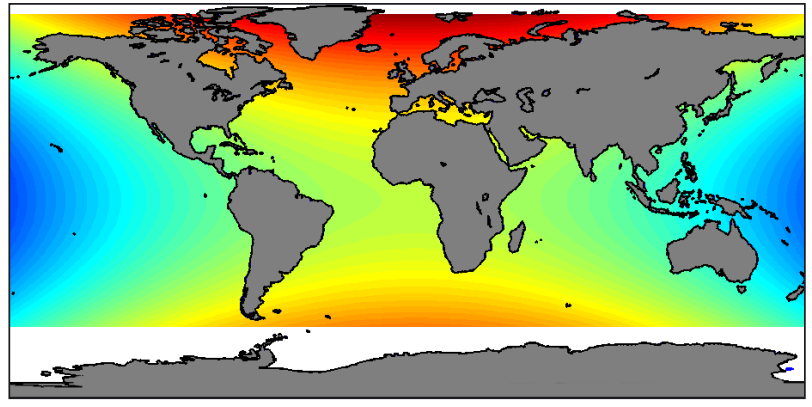

Mean fish species sizes (red: large; blue: small) vary among large marine ecosystems (LMEs) which contributes to their differential resilience to fisheries exploitation.

Image: Roger Pettipas

\section{INTRODUCTION}

The importance of species richness has long been at the centre of an evolving debate over the mechanisms underlying positive relationships between biodiversity and ecosystem functioning (e.g. Huston 1997, Loreau et al. 2001, Naeem \& Wright 2003, Hillebrand \& Matthiessen 2009, Reiss et al. 2009), where ecosystem functioning is defined as the processes and services provided by ecosystems and the ecosystem properties that sustain these provisions (Giller et al. 2004). Recently, there have been calls for analyses of links between biodiversity and ecosystem functioning that move beyond assessments of species richness towards trait-based analyses (e.g. McCann 2007, Palumbi et al. 2009, Reiss et al. 2009). These calls are founded partly on the belief that functional homogenization due to declines in trait variation can be decoupled from taxonomic homogenization (Olden et al. 2004). Addition- 
ally, notwithstanding the positive correlations between species richness and the functioning of ecosystems at regional and global scales (Worm et al. 2006, Frank et al. 2007), trait diversity, not species richness, may be the operative factor in determining ecosystem functioning (Huston 1997, Loreau et al. 2001, Norberg 2004, Solan et al. 2004). Thus, a clarification of whether species richness or correlated functional traits are more directly and operationally linked to ecosystem functioning is central to an identification of which of the many biodiversity components should be proactively conserved (Reiss et al. 2009, Hillebrand \& Matthiessen 2009).

The importance of this clarification has recently emerged in the context of furthering an understanding of the dynamics of exploited marine ecosystems. Here, the central questions have been what are the key biodiversity indicators (Palumbi et al. 2009) and how should they be measured so that important ecosystem properties can be monitored and preserved (e.g. Bianchi et al. 2000, Jennings 2005, Shin et al. 2005). The underlying assumption here is that positive ecosystem attributes (e.g. stability, optimal yield, sustained productivity, resilience to exploitation and environmental change) are strongly linked to diversity via operative links between species richness and functional traits such as body size, stress sensitivity, genetic diversity, and so on (Solan et al. 2004, Palumbi et al. 2009). An important implication of the possible existence of such linkages is that declines in a single or small number of these functional traits could reduce local ecosystem functioning more quickly than, or even in the absence of, declines in species richness (Hillebrand \& Matthiessen 2009).

In this context, body size is deemed to be a potentially important trait (both within and among species) due to its influence on population abundance, geographic distribution, species interactions, life history adaptations, and physiological profiles (Schaffer \& Elson 1975, Leggett \& Carscadden 1978, Blackburn \& Gaston 1994, Pauly 1998, Hildrew et al. 2007), and its role in structuring trophic interactions (Jennings et al. 2001, Hildrew et al. 2007, Shackell et al. 2010). Because most marine fisheries are size-selective, both targeting and incidentally removing the largest individuals and species, body size is also strongly correlated with vulnerability and extinction risk (Reynolds et al. 2005, Olden et al. 2007), and several investigators have used multiple size-based metrics as indicators of fisheries disturbance (e.g. Bianchi et al. 2000, Jennings 2005, Shin et al. 2005).

Given the worldwide size structuring effects of fisheries, we hypothesized that a global scale quantification of the magnitude of body size variations among ecosystems might reveal whether variation or direc- tional changes in this dominant species trait can contribute to the link between species richness and ecosystem functioning.

It is now known that the structure and functioning of multiple North Atlantic ecosystems have been altered by unprecedented fisheries collapses (e.g. Sherman \& Skjoldal 2002, Choi et al. 2005, Frank et al. 2007). Indeed, the North Atlantic is believed to be the only region of the world where large marine ecosystems (LMEs) have exhibited sequential collapses of fisheries operating at higher trophic levels and their replacement by fisheries focused on lower trophic levels (Essington et al. 2006, their Fig. 3). The most recent examples of exploitation-driven trophic cascades also come from the North Atlantic region (Frank et al. 2007, Baum \& Worm 2009). Given the magnitude and speed of these recent and dramatic changes in ecosystem functioning that include massive declines in fisheries yields and top predator biomass, as well as explosive increases in prey biomass and increased trophic imbalances, it may also be timely to ask: Are there characteristics of these North Atlantic marine fish assemblages that predisposed them to collapse relative to assemblages in other geographic areas such as the North Pacific, where the provision of ecosystem services have remained more stable (Essington et al. 2006, Briggs 2008, Courtenay et al. 2009)?

Our objectives in the present study were therefore 3-fold: (1) to investigate how body size distributions of marine fish species vary globally among LMEs, (2) to determine the relationship between average body size and species richness among LMEs, and (3) to assess whether body size variations, which have known responses to exploitation, may act as heretofore undetected 'missing metrics' in biodiversity-ecosystem functioning relationships (sensu Huston's 1997 'hidden treatments'). Within this third objective, we specifically addressed whether such 'missing metrics' may have contributed to (1) the previously reported positive relationships between species richness and LME functioning (Worm et al. 2006) and (2) the divergent outcomes of intensive fisheries exploitation on the stability of North Atlantic and North Pacific marine fish assemblages (Essington et al. 2006, Briggs 2008, Courtenay et al. 2009).

\section{MATERIALS AND METHODS}

Body size-species richness relationships and spatial variations in body size were examined in 56 of a recognized total of 64 LMEs (average area $>1$ million $\mathrm{km}^{2}$ ) worldwide (Sherman et al. 2009; Table 1, Fig. 1). Each LME was defined by coastal areas bounded by estuaries and the margins of continental shelves or by ocean 
Table 1. Descriptions, characteristics, and locations of 56 large marine ecosystems (LMEs) examined in the present study. Latitudes and longitudes were derived from approximate midpoints per LME based on GIS projections of LME boundaries obtained from www.lme.noaa.gov. LME species richness values and areas are from the Sea Around Us Project (2008). 'Region' refers to LMEs falling within 1 of 6 zones: North Atlantic (NA); South Atlantic (SA); North Pacific (NP); South Pacific (SP); Indian Ocean North (NI); Indian Ocean South (SI), see Fig. 1

\begin{tabular}{|c|c|c|c|c|c|c|c|}
\hline $\begin{array}{l}\text { LME } \\
\text { no. }\end{array}$ & LME & $\begin{array}{c}\text { Fish } \\
\text { species } \\
\text { richness }\end{array}$ & $\begin{array}{l}\text { Geometric } \\
\text { mean species } \\
\text { length }(\mathrm{cm})\end{array}$ & $\begin{array}{l}\text { Area } \\
\left(\mathrm{km}^{2}\right)\end{array}$ & Latitude & Longitude & Region \\
\hline 1 & East Bering Sea & 249 & 31.84 & 1186827 & 58.9 & -168.8 & NP \\
\hline 2 & Gulf of Alaska & 317 & 37.41 & 1474706 & 54.1 & -139.3 & NP \\
\hline 3 & California Current & 804 & 36.70 & 2215759 & 33.2 & -122.5 & NP \\
\hline 4 & Gulf of California & 383 & 30.01 & 222713 & 26.2 & -110.4 & NP \\
\hline 5 & Gulf of Mexico & 984 & 35.38 & 1536217 & 25.0 & -90.4 & NA \\
\hline 6 & Southeast US Continental Shelf & 1168 & 27.27 & 294927 & 30.3 & -78.8 & NA \\
\hline 7 & Northeast US Continental Shelf & 645 & 46.92 & 310146 & 41.0 & -70.4 & NA \\
\hline 8 & Scotian Shelf & 197 & 64.28 & 414534 & 47.0 & -61.7 & NA \\
\hline 9 & Newfoundland-Labrador Shelf & 171 & 52.60 & 681296 & 49.5 & -53.0 & NA \\
\hline 10 & Insular Pacific-Hawaiian & 838 & 31.19 & 982811 & 23.8 & -166.4 & NP \\
\hline 11 & Pacific Central-American Coastal & 943 & 35.39 & 1990321 & 11.5 & -93.0 & NP \\
\hline 12 & Caribbean Sea & 1563 & 25.70 & 3274085 & 16.6 & -74.9 & NA \\
\hline 13 & Humboldt Current & 748 & 33.15 & 2559043 & -30.4 & -73.2 & SP \\
\hline 14 & Patagonian Shelf & 334 & 46.67 & 1167969 & -46.3 & -61.6 & SA \\
\hline 15 & South Brazil Shelf & 966 & 42.39 & 567996 & -27.5 & -46.4 & SA \\
\hline 16 & East Brazil Shelf & 894 & 41.95 & 1079113 & -10.1 & -34.2 & SA \\
\hline 17 & North Brazil Shelf & 933 & 37.46 & 1058516 & 4.6 & -51.2 & NA \\
\hline 18 & West Greenland Shelf & 157 & 45.05 & 365548 & 70.2 & -57.1 & NA \\
\hline 19 & Greenland Sea & 162 & 41.22 & 1171612 & 75.5 & -11.8 & NA \\
\hline 20 & Barents Sea & 59 & 38.52 & 1865429 & 76.0 & 37.3 & NA \\
\hline 21 & Norwegian Sea & 232 & 53.76 & 1102919 & 68.0 & 3.7 & NA \\
\hline 22 & North Sea & 190 & 60.89 & 695626 & 57.4 & 2.8 & NA \\
\hline 23 & Baltic Sea & 157 & 53.85 & 394265 & 58.9 & 19.7 & NA \\
\hline 24 & Celtic-Biscay Shelf & 317 & 56.90 & 759958 & 51.7 & -7.6 & NA \\
\hline 25 & Iberian Coastal & 617 & 45.45 & 303958 & 41.1 & -8.8 & NA \\
\hline 26 & Mediterranean Sea & 711 & 42.02 & 2529210 & 37.1 & 16.7 & NA \\
\hline 27 & Canary Current & 1263 & 40.44 & 1125327 & 24.7 & -15.3 & NA \\
\hline 28 & Guinea Current & 724 & 45.96 & 1927373 & 3.4 & -3.6 & NA \\
\hline 29 & Benguela Current & 815 & 46.27 & 1462580 & -21.3 & 12.5 & SA \\
\hline 30 & Agulhas Current & 1381 & 32.78 & 2632932 & -22.1 & 40.8 & SI \\
\hline 31 & Somali Coastal Current & 688 & 37.01 & 843937 & 0.5 & 44.6 & NI \\
\hline 32 & Arabian Sea & 941 & 37.78 & 3945355 & 16.3 & 62.8 & NI \\
\hline 33 & Red Sea & 1217 & 27.31 & 462210 & 20.6 & 38.6 & NI \\
\hline 34 & Bay of Bengal & 693 & 43.03 & 3679296 & 10.8 & 89.4 & NI \\
\hline 35 & Gulf of Thailand & 618 & 38.39 & 381681 & 8.7 & 102.3 & NI \\
\hline 36 & South China Sea & 3822 & 23.96 & 3183503 & 11.9 & 112.4 & NP \\
\hline 37 & Sulu-Celebes Sea & 1161 & 33.35 & 1017861 & 6.6 & 122.0 & NP \\
\hline 38 & Indonesian Sea & 2426 & 24.75 & 2275957 & -4.4 & 121.9 & SI \\
\hline 39 & North Australian Shelf & 1836 & 27.07 & 782956 & -12.6 & 135.2 & SP \\
\hline 40 & Northeast Australian Shelf & 1725 & 22.12 & 1284441 & -17.2 & 150.8 & SP \\
\hline 41 & East Central Australian Shelf & 1239 & 32.47 & 654158 & -29.1 & 154.9 & SP \\
\hline 42 & Southeast Australian Shelf & 246 & 34.05 & 1192306 & -41.0 & 145.3 & SP \\
\hline 43 & Southwest Australian Shelf & 471 & 37.29 & 1052046 & -35.1 & 124.1 & SI \\
\hline 44 & West Central Australian Shelf & 470 & 37.22 & 545539 & -27.3 & 112.1 & SI \\
\hline 45 & Northwest Australian Shelf & 1076 & 27.32 & 915060 & -16.7 & 119.1 & SI \\
\hline 46 & New Zealand Shelf & 914 & 34.44 & 967616 & -40.8 & 171.9 & SP \\
\hline 47 & East China Sea & 1069 & 39.34 & 780554 & 29.6 & 125.4 & NP \\
\hline 48 & Yellow Sea & 1906 & 30.50 & 440387 & 36.5 & 122.7 & NP \\
\hline 49 & Kuroshio Current & 1444 & 30.91 & 1322524 & 31.0 & 134.7 & NP \\
\hline 50 & Sea of Japan & 558 & 39.94 & 987376 & 41.3 & 135.7 & NP \\
\hline 51 & Oyashio Current & 37 & 47.63 & 532831 & 45.2 & 151.6 & NP \\
\hline 52 & Okhotsk Sea & 391 & 31.33 & 1557816 & 53.8 & 148.9 & NP \\
\hline 53 & West Bering Sea & 311 & 31.38 & 2170639 & 57.5 & -175.5 & NP \\
\hline 59 & Iceland Shelf/Sea & 152 & 65.86 & 518020 & 66.6 & -17.6 & NA \\
\hline 60 & Faroe Plateau & 174 & 63.62 & 150558 & 60.6 & -11.2 & NA \\
\hline 62 & Black Sea & 193 & 44.59 & 461958 & 43.5 & 34.4 & NA \\
\hline
\end{tabular}




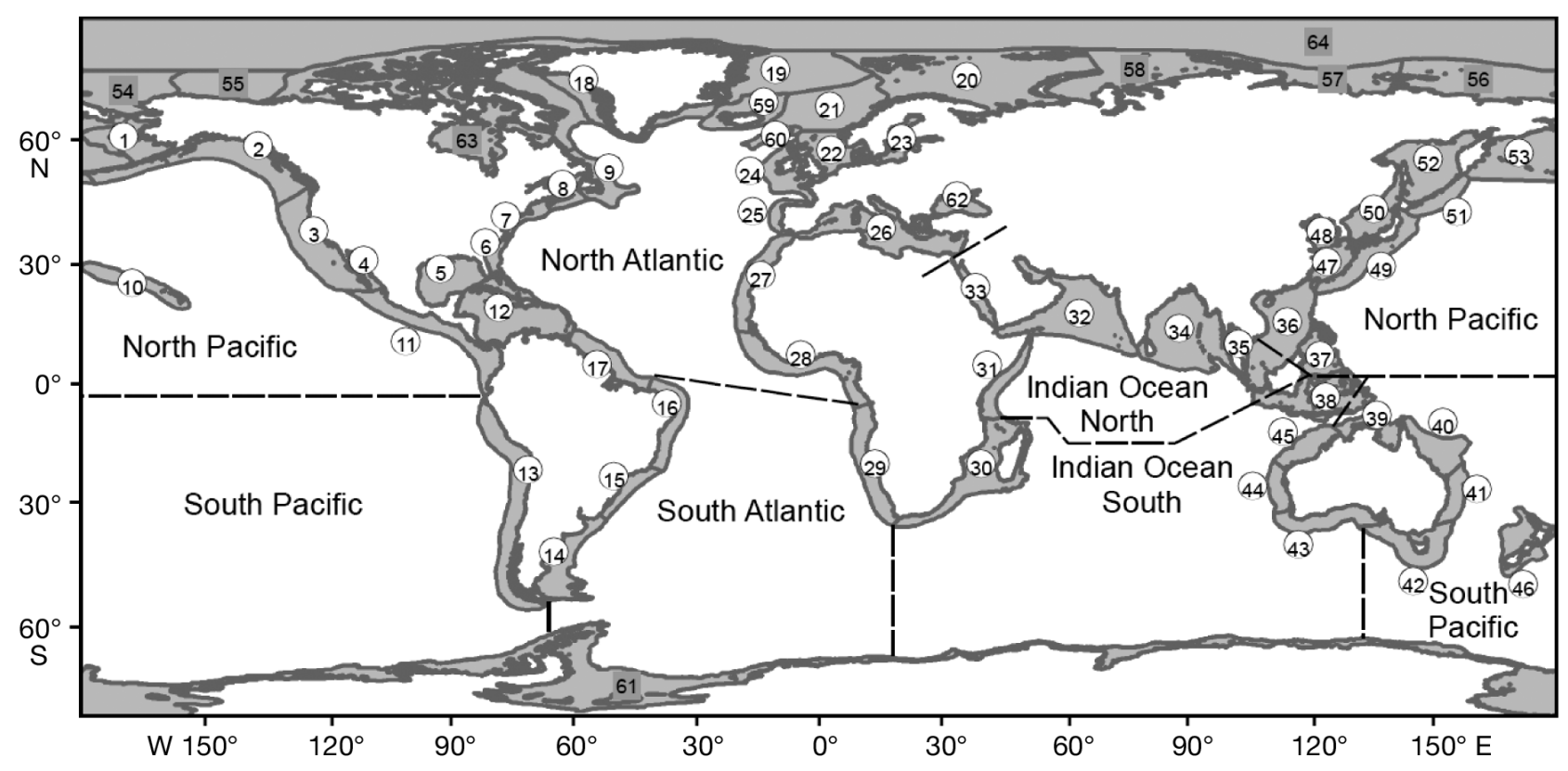

Fig. 1. Extent (light grey shading) and boundaries (dark grey lines) (from www.lme.noaa.gov/) of 64 large marine ecosystems (LMEs). Dashed lines outline the boundaries of 6 ocean regions and numbers identify 64 LMEs including the 56 examined in the present study (white circles, see Table 1)

currents. Collectively, the 64 LMEs encompass 80 to $90 \%$ of the world's annual fisheries harvest (Sherman et al. 2009). The 8 LMEs excluded from our analyses included 7 boreal areas and 1 Antarctic LME. These were eliminated because measures of species composition and/or richness were incomplete or unreliable (Mora et al. 2008). Lists of species along with their maximum total length $(\mathrm{cm})$ were compiled for each of the 56 LMEs using the Sea Around Us Project (2008) website which is linked to the Fishbase database (Froese \& Pauly 2008). In these data sets, species presence within LMEs is based on referenced occurrence data (Froese \& Pauly 2008). The compiled data set included 12151 species from 423 families and included approximately $97 \%$ of the marine fish species listed in Fishbase and $76 \%$ of all known marine fish species (Olden et al. 2007). For each LME we constructed sizefrequency distributions of the species assemblage and derived estimates of geometric mean length among species and skewness of the ln-transformed species size distributions using JMPin 4.0.4 (SAS Institute 2000). The resulting geometric mean lengths per LME (among all species) were binned into 5 categories: $<30$, 30 to $<35,35$ to $<40,40$ to $<50$, and $>50 \mathrm{~cm}$.

Our analysis rests on the assumption that variation about the baseline state of an ecosystem can be reliably characterized by a single trait value (in our case maximum length per species). This assumption is imposed by the absence of more detailed data for the ecosystems investigated and, for similar reasons, is characteristic of those employed in earlier large-scale analyses focused on terrestrial and aquatic systems (Blackburn \& Gaston 1994, Macpherson \& Duarte 1994, McDowall 1994, Pauly 1998, Roy et al. 2000, Knouft 2004, Olden et al. 2007). However, even such baseline information per species has proven useful in analyzing changes in marine ecosystems. For example, within multi-species fisheries models that assume sizeselective fishing mortality, mean maximum lengths among species (derived by assigning a Fishbase maximum length to each species) are predicted to decline with decreasing biomass within single ecosystems and across an ensemble of 31 ecosystems (Worm et al. 2009). Furthermore, a $22 \%$ decline (since 1959) in mean maximum fish length has been reported based on a global compilation of marine ecosystem surveys (Worm et al. 2009). Such predicted and observed temporal dynamics in mean maximum lengths suggest that even characterizations using a single trait per species are useful in evaluating the ecosystem effects of fishing.

A global portrayal of the baseline trait variation among LMEs was developed by mapping mean species size against the approximate centre point of each LME (latitudes, longitudes, and ocean regions for each LME provided in Table 1 \& Fig. 1). Given the potential for species richness to mask variation in other species traits associated with ecosystem functioning, we evaluated the relationship between body size and species richness among LMEs. We similarly evaluated the relationship between body size and skewness of the size frequency distribution. 
We also conducted an inter-comparison of the species size relationships in North Atlantic and North Pacific LMEs in an effort to evaluate the extent to which differences in body size relationships might contribute to the widely differing trends in commercial catch rates between the 2 areas (Essington et al. 2006). Briggs (2008) suggested that these divergent responses to intensive exploitation were the product of differences in species richness, a claim discounted by Courtenay et al. (2009), who argued that management histories alone account for the differences.

Finally, to directly explore poten-

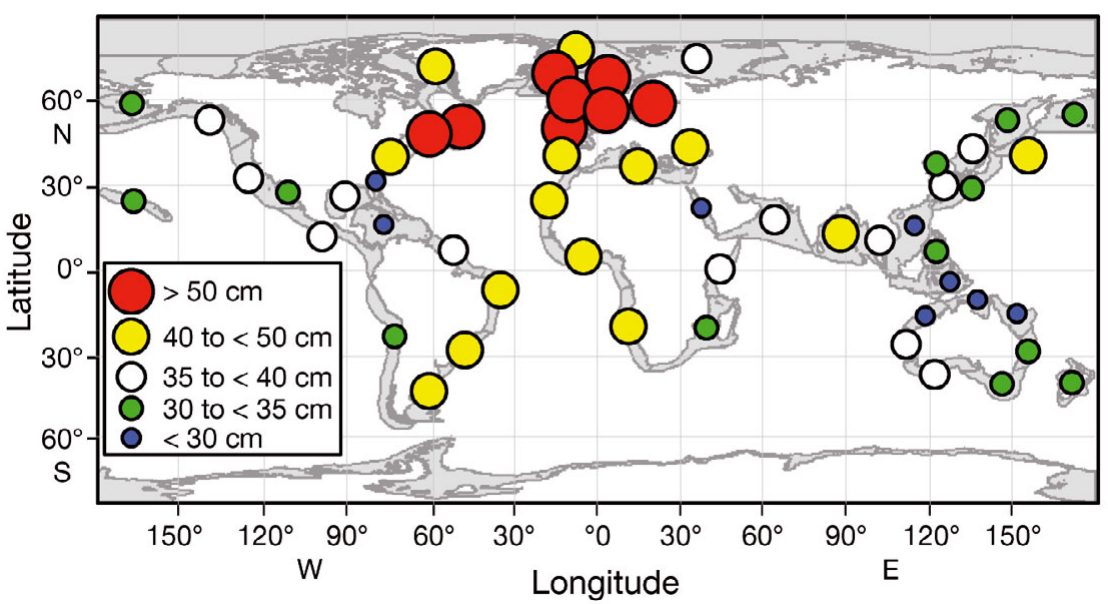

Fig. 2. Geometric mean maximum length per fish species (symbol colours and sizes) within the 56 large marine ecosystems (LMEs) examined in the present study. Dark grey lines indicate boundaries of 64 LMEs identified in Fig. 1 and the light grey tial interactions between body size, shading indicates areas within LMEs

species richness, and decadal-scale changes in marine ecosystem functioning at a global scale, we reanalyzed data from a subset of 30 of the 56 LMEs that showed evidence of fishing down the food web (data derived from Essington et al. 2006) to investigate the relationship between geometric mean maximum fish length, species richness, and fisheries yield. As our measure of yield we used published estimates of the instantaneous rate of change in annual commercial catches of top predators (trophic level $>4$ ). These relationships were derived from the time interval 1950-2003, during periods when the trophic level of the catch declined in each LME (Essington et al. 2006).

\section{RESULTS}

\section{Global patterns among LMEs}

Species lengths

A 3-fold difference $(22.1$ to $65.9 \mathrm{~cm})$ in geometric mean maximum fish species lengths was observed among LMEs (Fig. 2, Table 1). The largest mean species lengths $(>50 \mathrm{~cm})$ occurred exclusively in the Northern Hemisphere (eastern and western North Atlantic; Fig. 2). At latitudes $>35^{\circ} \mathrm{N}$ and $\mathrm{S}$ in the Atlantic, all but one of the LMEs (Barents Sea) had mean lengths $>40 \mathrm{~cm}$ - the second largest size category evaluated. In contrast, the smallest mean body sizes $(<30 \mathrm{~cm})$ were found mainly at low latitudes in both hemispheres. Only 2 of 30 LMEs outside the Atlantic region (Bay of Bengal, Oyashio Current) had geometric mean maximum lengths $>40 \mathrm{~cm}$ (Fig. 2).

Significant positive correlations between latitude and geometric mean species sizes were evident among
LMEs in the North Atlantic $(r=0.50, p=0.02, n=21)$, South Pacific $(\mathrm{r}=0.86, \mathrm{p}=0.03, \mathrm{n}=6)$, and Indian Ocean (southern latitudes; $r=0.94, p=0.02, n=5$ ). The few South Atlantic LMEs yielded a strong but nonsignificant correlation $(\mathrm{r}=0.65, \mathrm{p}=0.33, \mathrm{n}=4)$, while LMEs within the North Pacific $(r=0.25, p=0.36, n=15)$ and Indian Ocean (north; $\mathrm{r}=-0.53, \mathrm{p}=0.36, \mathrm{n}=5$ ) showed little or no evidence of positive relationships between latitude and mean species size per LME. At higher latitudes in the Northern Hemisphere, geometric mean lengths declined longitudinally away from the Eastern Atlantic peak. In the Southern Hemisphere, a similar pattern of maximum values in the Atlantic was observed. Together, latitude and longitude explained $50 \%$ of the global variation in mean fish species lengths $\left(F_{4,51}=12.67, \mathrm{p}<0.0001\right.$; Fig. $\left.3 \mathrm{a}\right)$, while longitude alone (the best single variable) explained only $30 \%$ of the spatial variation (data not shown).

Relationships between species richness, mean species lengths, and skewness

Among LMEs arranged spatially, the relationship between species richness and mean species length was complex, while non-spatial analyses revealed a strong negative correlation between these 2 ecosystem metrics. The poleward increases in geometric mean species lengths (with greatest range across the North Atlantic region; Fig. 3a) contrasted with the strong poleward declines in species richness among all LMEs (Fig. 3b). However, the strong, non-linear trends in mean lengths across longitudes (Fig. 3a) were not matched by strong, non-linear longitudinal variations in species richness (Fig. 3b). Geometric mean maxi- 
mum fish length declined exponentially with increasing species richness ( $\mathrm{r}=-0.68$; Fig. 4). Among LMEs, variability in mean species lengths increased as species richness declined (Fig. 4). For example, among the 22 LMEs having species richness values <500, geometric mean lengths varied more than 2-fold (Fig. 4).
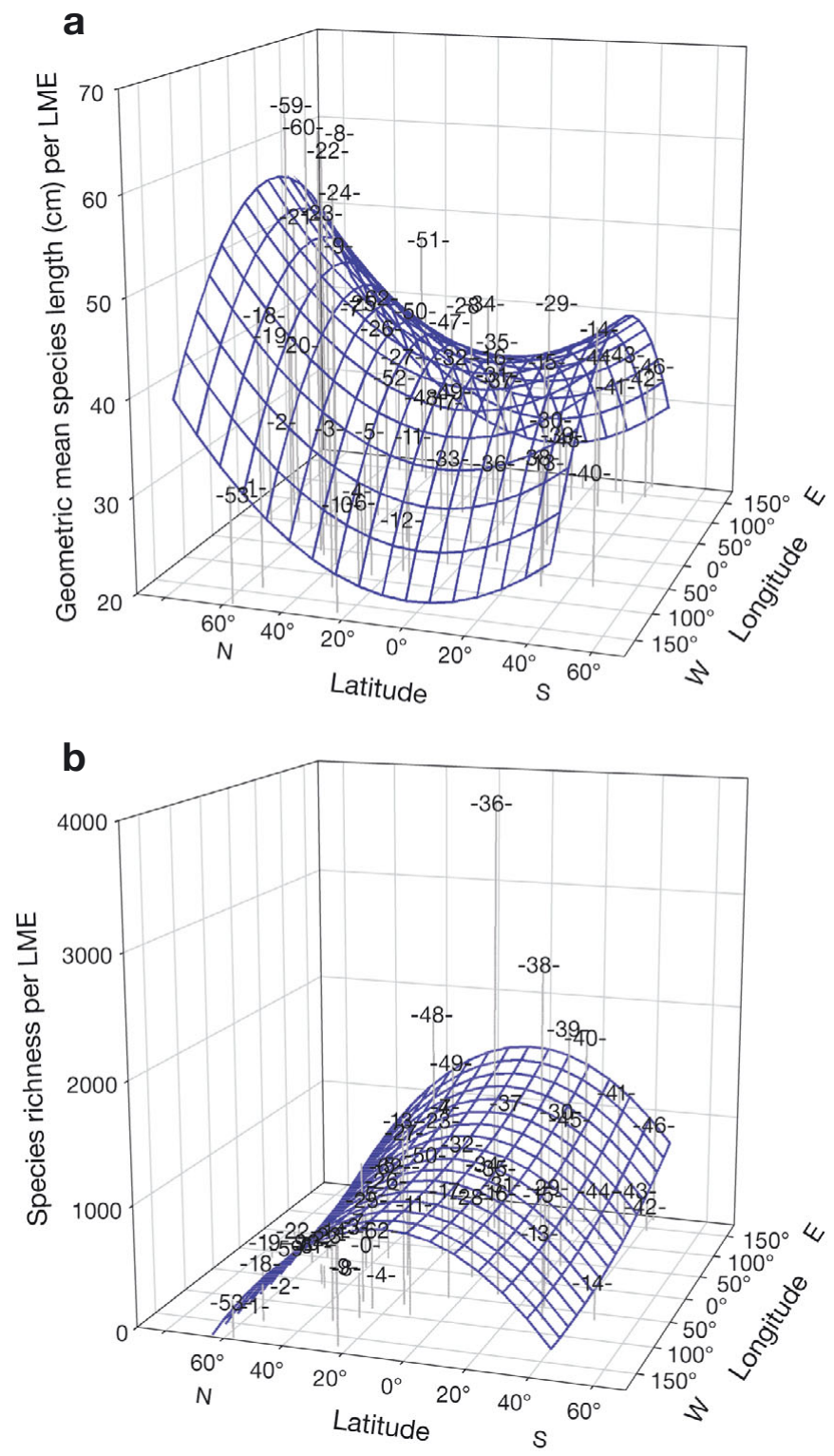

Fig. 3. (a) Geometric mean maximum length per fish species within 56 large marine ecosystems (LMEs) in relation to LMEs latitudinal and longitudinal midpoints. Fitted parabolic surface $\left(r^{2}=0.50\right)$ shows the significant $(p<0.001)$, non-linear influences of both latitude and longitude on mean fish size. (b) Species richness within 56 LMEs in relation to LME latitudinal and longitudinal midpoints. Fitted parabolic surface $\left(\mathrm{r}^{2}=\right.$ $0.42, \mathrm{p}<0.0001)$ is shown, although only latitude is a significant (non-linear) main effect $(\mathrm{p}<0.001$; longitude, $\mathrm{p}>$ 0.05). Data labels correspond to LME numbers identified in Fig. 1 \& Table 1
Deviations from a fitted relationship between geometric mean lengths and species richness (Fig. 4) were evident in the 8 North Atlantic LMEs with geometric mean species lengths $>50 \mathrm{~cm}$ (body sizes relative to species richness greater than expected), and in the North Pacific, Greenland, and Barents Sea LMEs (lower than expected body sizes).

The skewness of species size distributions also varied with geometric mean species lengths. In most LMEs, species size distributions were positively skewed with an over-representation of smaller body sizes (Fig. 5). However, skewness in 5 North Atlantic LMEs was negative. These LMEs exhibited length distributions domi-

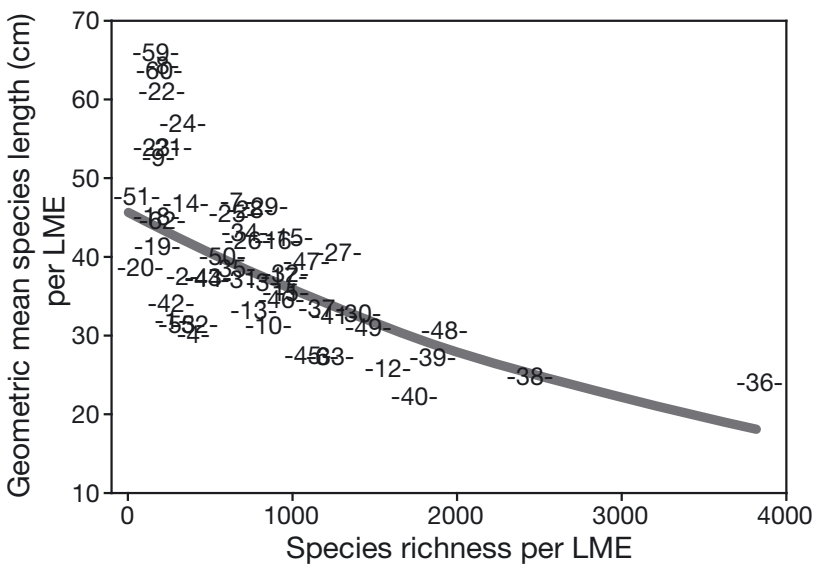

Fig. 4. Negative exponential relationship between species richness (SR) and geometric mean maximum species lengths (GML) among fishes within 56 large marine ecosystems (LMEs), where GML $=46.868 \mathrm{e}^{-0.0003 \mathrm{SR}}(\mathrm{r}=-0.68)$. Data labels correspond to LMEs identified in Fig. 1 \& Table 1

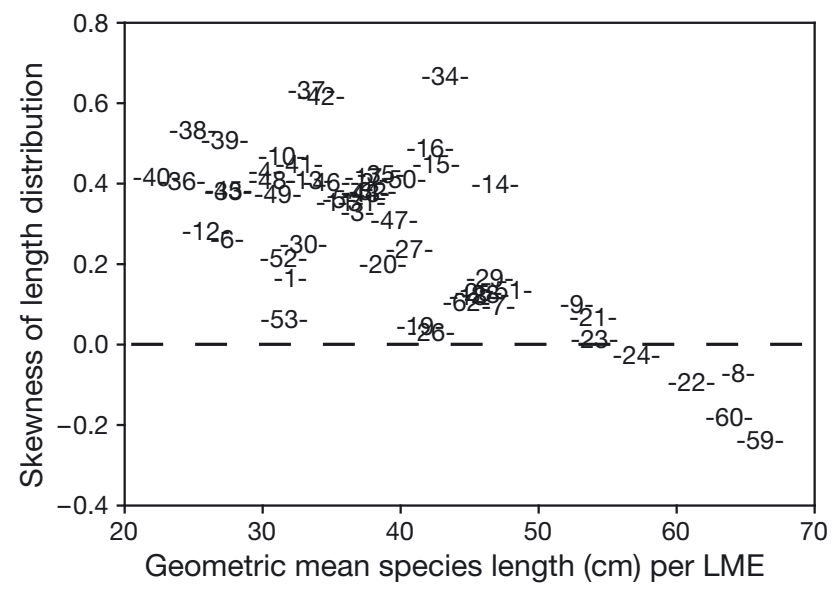

Fig. 5. Negative correlation between geometric mean species length per large marine ecosystem (LME) and the skewness of ln-transformed length distributions $(\mathrm{r}=-0.73)$ among 56 LMEs. Positive and negative skewness indicate dominance by fishes with small and large lengths, respectively. All areas with skewness values $<0$ are from North Atlantic LMEs (Celtic-Biscay Shelf, Scotian Shelf, North Sea, Faroe Plateau and Iceland Shelf) 


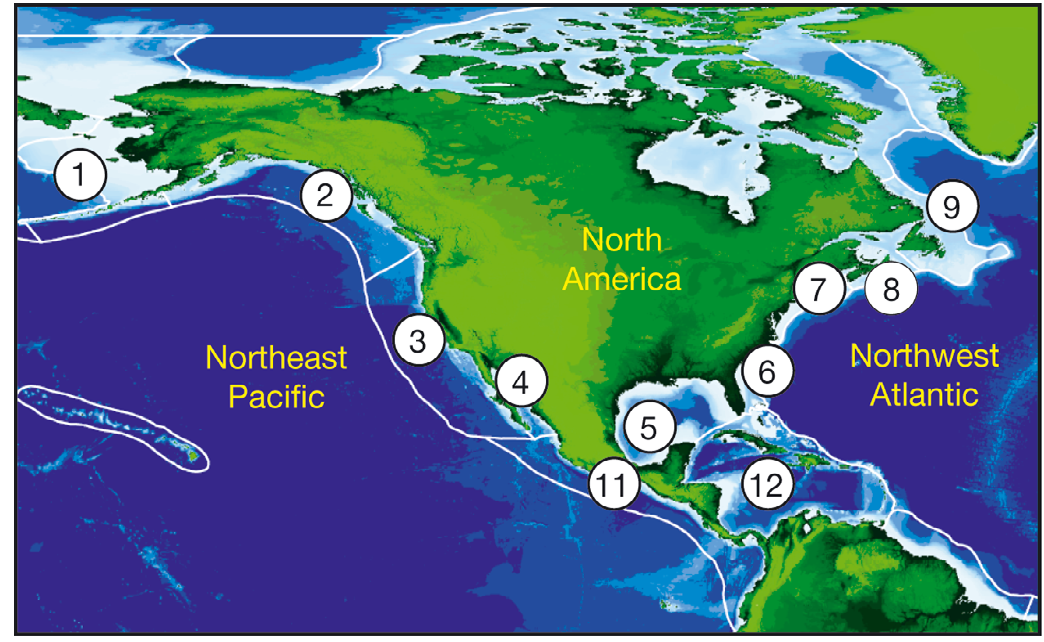

Fig. 6. Locations of the 11 large marine ecosystems (LMEs) used for the comparison of fish species size structures between the western North Atlantic and eastern North Pacific; labels correspond to those in Table 1

Fish assemblage size structures between LMEs with similar species richness

Pairwise comparisons of Northeast Pacific and Northeast Atlantic LMEs containing similar or identical species numbers with their associated species size structure also provide insights into the potential impact of size-selective exploitation separate from the potential influence of species richness. For example, exploitation of large-bodied species would negatively impact 50 and $28 \%$ of the species in the Norwegian Shelf and East Bering Sea LMEs, respectively (Fig. 9). Similarly, in the 2 LMEs with identical species numbers ( $\mathrm{n}=317$, Celtic-Biscay Shelf and Gulf of Alaska) the former had $52 \%$ largebodied species, while the latter had

nated by relatively large body size classes and the largest geometric mean species lengths (Fig. 5). Among all LMEs, the skewness of the ln-transformed LME length-frequency distributions varied inversely with geometric mean maximum lengths ( $\mathrm{r}=-0.73$; Fig. 5). These skewness patterns, when combined with the observed negative relationships between species richness and geometric mean length (Fig. 4), suggest that, in general, ecosystems with the lowest species richness are dominated by large-bodied species.

\section{North Atlantic and North Pacific comparisons}

Latitudinal gradients in species richness and mean species lengths

We examined differences in species richness, geometric mean species lengths, and the skewness of species size-frequency distributions in 5 Northeast Pacific ( $\mathrm{n}=1709$ total species) and 6 Northwest Atlantic ( $\mathrm{n}=$ 2117 total species) LMEs (Fig. 6) in an attempt to clarify the contributions of species richness and body size to the differences in fisheries stability between the 2 areas. Poleward declines in species richness were apparent along both Atlantic and Pacific coasts (Fig. 7), but poleward increases in geometric mean species lengths occurred only in the Atlantic (Fig. 7). The percentages of large-bodied species also differed between coasts. The Northeast Pacific and 3 Atlantic LMEs located $<35^{\circ} \mathrm{N}$ had $\leq 35 \%$ large bodied species (Fig. 8), whereas 3 Northwest Atlantic LMEs (Nos. 7, 8, and 9) located $>35^{\circ} \mathrm{N}$ had higher frequencies (45 to $57 \%$ ) of large-bodied species (Fig. 8).
$35 \%$ (Fig. 9). In addition to the patterns shown in Figs. $7 \& 8$, the contrasts revealed in Fig. 9 illustrate the greater potential impact of large size-biased fisheries on North Atlantic LMEs relative to others, notwithstanding their similarities in species richness.
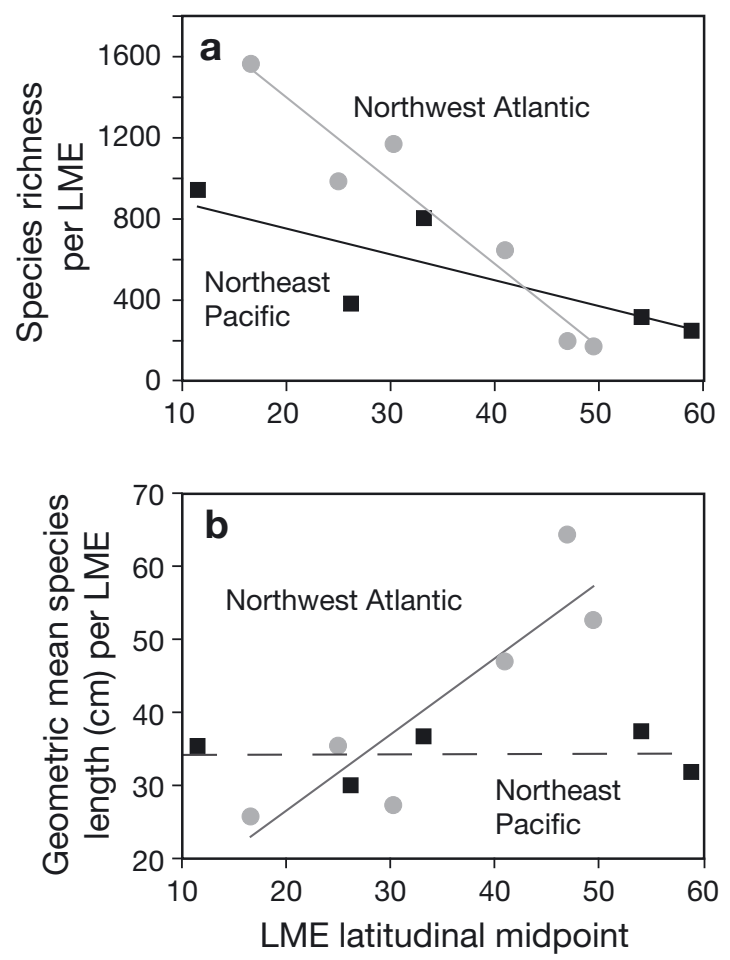

Fig. 7. Latitudinal variation in (a) species richness and (b) geometric mean species length between (๑) 6 Northwest Atlantic and (घ) 5 Northeast Pacific large marine ecosystems (LMEs) (see Fig. 6) 

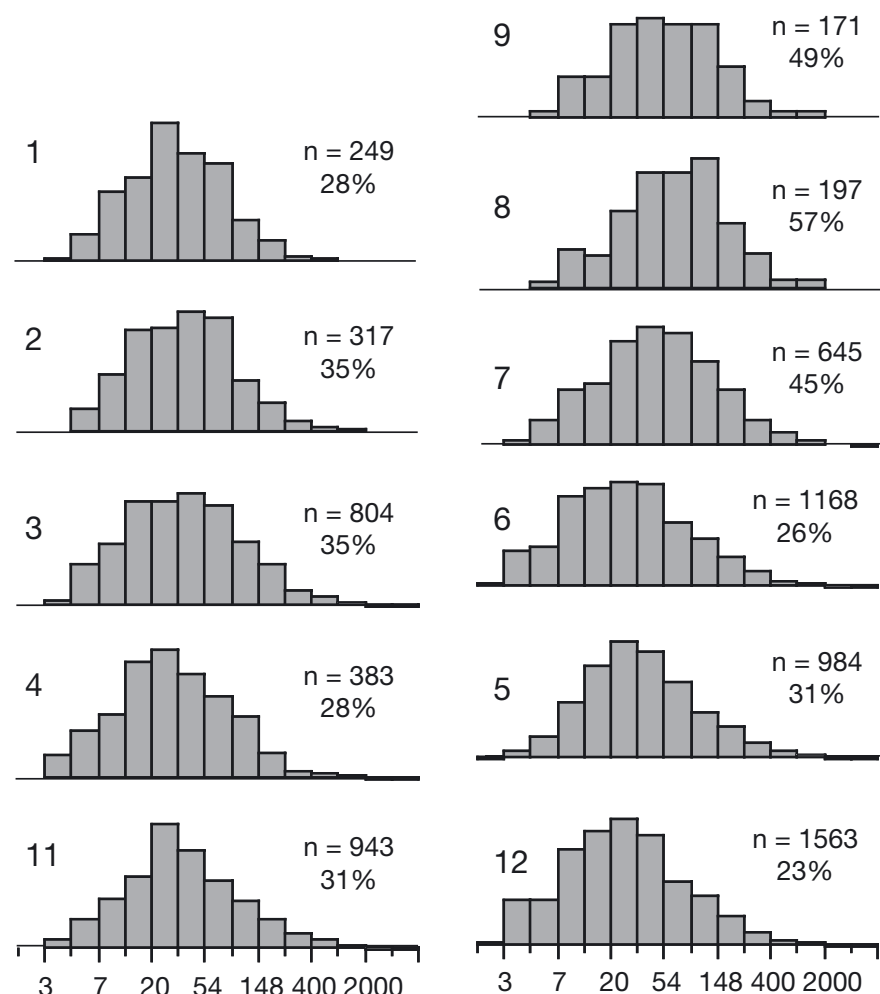

Fish species length $(\mathrm{cm})$

Fig. 8. Comparisons of proportional species length distributions among 6 Northwest Atlantic and 5 Northwest Pacific large marine ecosystems (LMEs) (see Fig. 6). Also given are the total number of species per LME and the percentage of species $\geq 55 \mathrm{~cm}$ in maximum length within each LME

\section{Ecosystem functioning - influence of body size and species richness}

Trends in the landings of commercially exploited species are one of the most widely quantified measures of marine ecosystem functioning. Actual landings data were not directly available for all of the LMEs we investigated, but based on rates of change in landings of top predators within 30 of the 56 LMEs we analyzed (Essington et al. 2006), changes in long-term fisheries yields were strongly and negatively correlated with geometric mean maximum species size $(\mathrm{r}=-0.63$; Fig. 10a). In contrast, log-transformed species richness was positively, but weakly, correlated with rates of change in fisheries yields $(r=0.43$; Fig. 10b).

\section{DISCUSSION}

Several authors have recently sought a clearer definition of the inter-relationships between taxonomic diversity, functional diversity, and community structure as a means of clarifying the contribution of species
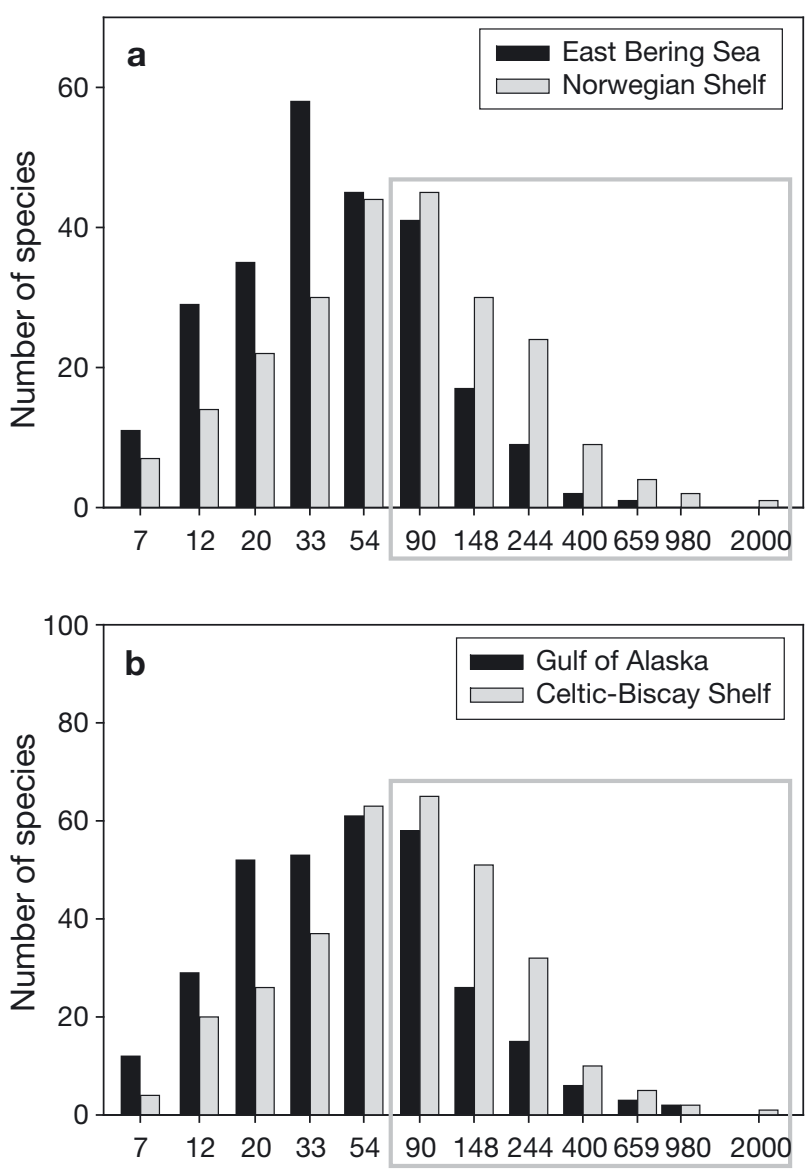

Fish species length $(\mathrm{cm})$

Fig. 9. Frequency distributions of fish species lengths from Northeast Pacific and Northeast Atlantic large marine ecosystems (LMEs) having similar or identical species richness. (a) East Bering Sea ( $\mathrm{n}=249$ species) versus Norwegian Shelf ( $\mathrm{n}=$ 232 species), illustrating that the Norwegian Shelf has almost twice as many species $\geq 55 \mathrm{~cm}$ in maximum length (50 versus $28 \%$ within boxed length categories). (b) Gulf of Alaska ( $\mathrm{n}=$ 317 species) versus Celtic-Biscay Shelf ( $n=317$ species), illustrating that the latter has $52 \%$ species $\geq 55 \mathrm{~cm}$ in maximum length, while the former has $35 \%$ species $\geq 55 \mathrm{~cm}$ in maximum length. Labelled fish species length bins identify the upper limits

richness to the structure and stability of ecosystems (Loreau et al. 2001, Hillebrand \& Matthiessen 2009, Reiss et al. 2009). Meanwhile, a parallel and growing interest in the impact of species- and size-selective fisheries on the productivity (Shin et al. 2005) and stability (Worm et al. 2006, 2009, Palumbi et al. 2009) of marine ecosystems has developed. While these 2 avenues of enquiry have followed largely separate paths, our results suggest a strong connection between the two and lead us to hypothesize that spatial variation in body size distributions, whether natural (e.g. Bergmann's Rule) or induced by size- and/or speciesspecific exploitation, may underlie the previously re- 


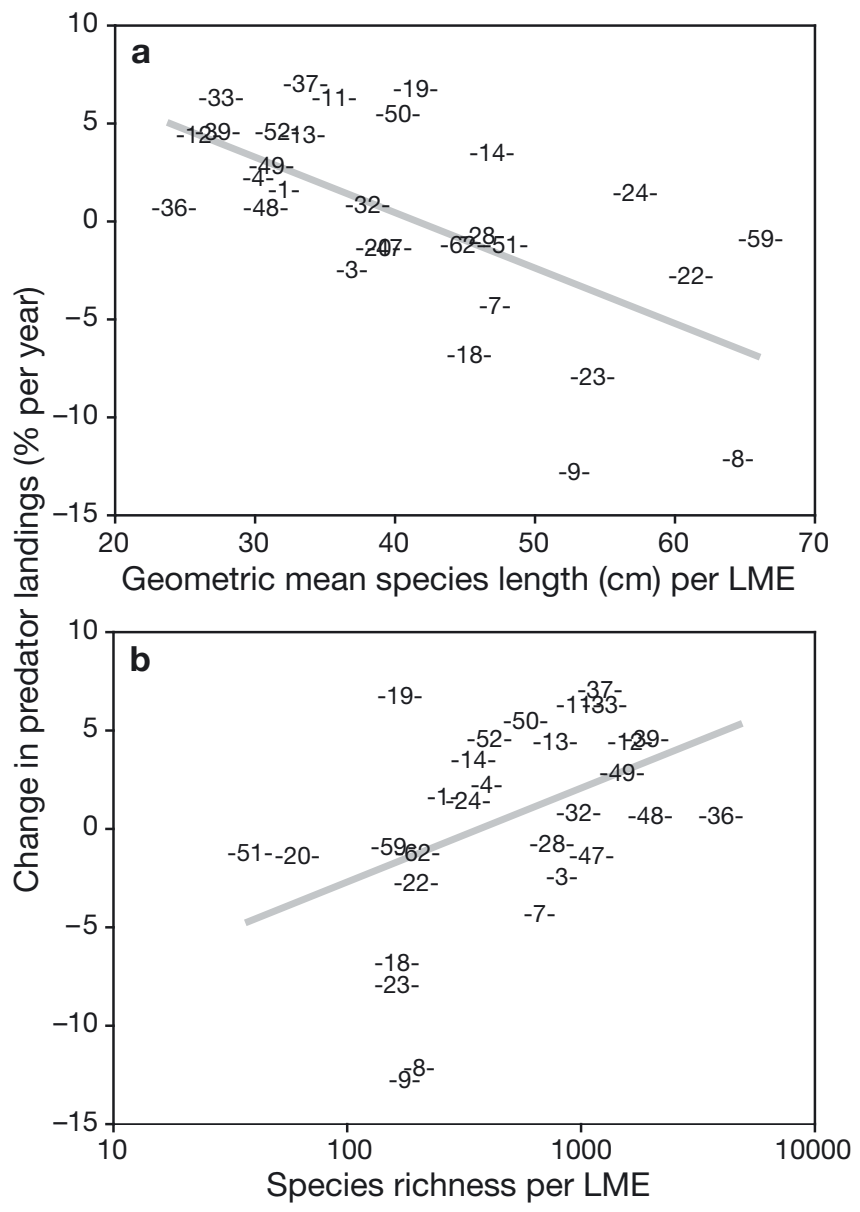

Fig. 10. (a) Negative correlation $(r=-0.63)$ between geometric mean fish species length per large marine ecosystem (LME) and the annual percent change in predator landings per year among 30 LMEs during periods when the trophic level of the catch declined in each LME. (b) Positive correlation $(r=0.43)$ between species richness per LME and the annual percent change in predator landings per year among 30 LMEs during periods when the trophic level of the catch declined in each LME. Data on changing predator catch rates were derived from Essington et al. (2006). Data labels correspond to LMEs identified in Table 1

ported positive associations between species richness and marine ecosystem functioning at a global scale.

\section{Global patterns among LMEs}

The global pattern of size variation among LMEs we document here (Fig. 2) reveals an important, but previously overlooked, spatial structure in fish species sizes across both latitude and longitude. In North Atlantic, South Pacific, and Indian Ocean (southern latitudes) LMEs, patterns of significant increases in mean species lengths with latitude (Fig. 3a) conform to one of the most widespread ecogeographical (Bergmann's) rules
(Blackburn et al. 1999, Millien et al. 2006, Olson et al. 2009). Although Bergmann's original definition and mechanism related only to endotherms (Watt et al. 2010), patterns of increasing body size with latitude have since been documented among and within ectotherms (Lindsey 1966, Millien et al. 2006) and specifically among North American freshwater (McDowall 1994, Knouft 2004) and Eastern Atlantic marine fish assemblages (Macpherson \& Duarte 1994). However, these latitudinal size gradients were evident only in some regions and there they closely paralleled variation in average annual sea surface temperature (Belkin 2009; Fig. 11) and maximum summer net primary productivity (Huston \& Wolverton 2009). Sea surface temperatures and, to a lesser extent, primary productivity (Huston \& Wolverton 2009) also exhibited latitudinal gradients outside the North Atlantic (Fig. 11). However, corresponding body size gradients were absent in the North Pacific, suggesting that, beyond the North Atlantic, trends in contemporary temperature and primary productivity are not, in themselves, sufficient to explain the assemblage size structures characteristic of Northern Hemisphere LMEs.

Environmental selection operating on species-specific life history characteristics and metabolic constraints on maximum fish sizes may both contribute to the latitudinal contrasts in body size distributions. In fishes, maximum body sizes are correlated with other key life history parameters such as survival, growth rate, and fecundity (Hutchings 2002). Additionally, at large spatial scales, contrasts in assemblage size structure and life history characteristics among species, including lower size-specific natural mortality, growth rates, and generally larger maximum sizes among temperate relative to tropical marine fishes, have been hypothesized to reflect temperature-specific metabolic rates (Pauly 1998). If life history characteristics reflect natural selection (see Hutchings 2002), the varying size-frequency distributions we documented among LMEs (Fig. 5) may reflect life history adaptations and species sorting to match size-related traits to local habitat conditions (Loreau et al. 2001, Norberg 2004). For example, in seasonal environments at high latitudes where delayed age and sizes at maturity and iteroparity act as a buffer against low and variable early life stage survival, larger individuals predominate (Schaffer \& Elson 1975, Leggett \& Carscadden 1978, Hutchings 2002). Moreover, if life history attributes associated with large maximum sizes contribute to the larger average size of species at high latitudes (Figs. 2 \& 3), intraspecific declines in average body sizes due to size-selective exploitation would be expected to have strong negative consequences, particularly if small maximum sizes and associated semelparity continue to be selected against by their environment(s). Taken together, the potential 


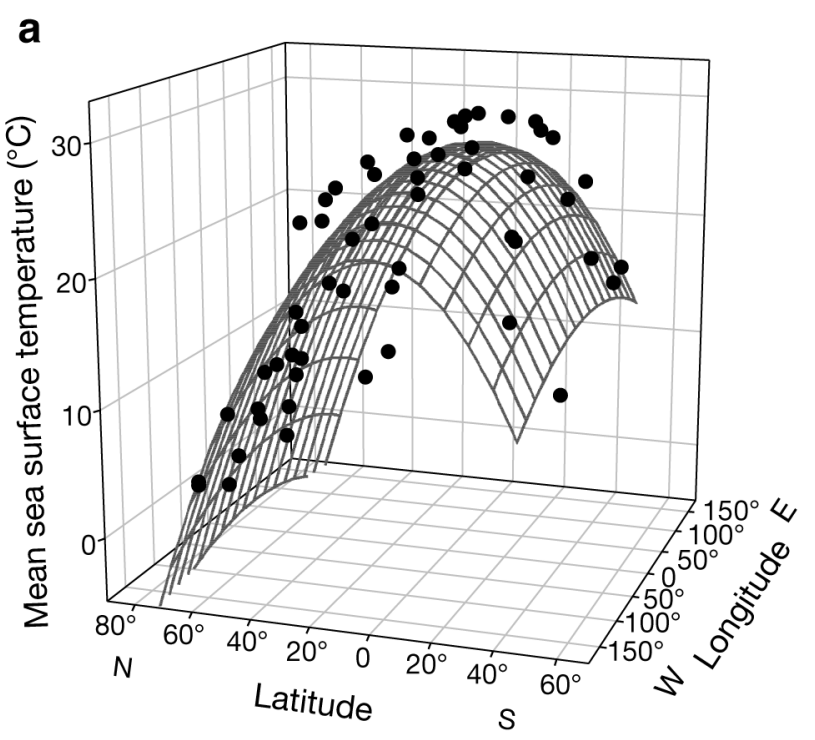

Fig. 11. (a) Mean sea surface temperature (SST) among 56 large marine ecosystems (LMEs) in relation to LME latitudinal and longitudinal midpoints. Data were derived from the averages of SST time series reported by Belkin (2009). As was done for body size and species richness (Figs. $2 \& 3$ ), the mesh plot overlay illustrates the parabolic fit to the data $\left(r^{2}=0.86\right.$, p $\left.<0.0001\right)$ with latitude as a dominant significant (non-linear) main effect $(p<0.001$; longitude, $p=0.02)$. (b) Mean SST plotted against LME latitudinal midpoints. The 56 LMEs were divided into Atlantic (including Baltic, Mediterranean, and Black Sea) and Outside Atlantic regions; between the 2 groups, at equivalent northern latitudes, there is much similarity in SST

for multiple size-related changes in life history parameters among and within species as a consequence of exploitation suggest that rebuilding and preservation of these species and ecosystem-level size structures should be an explicit goal of fisheries management (see also Berkeley et al. 2004, Planque et al. 2010 for conservation approaches to rebuild size structure).

Despite some longitudinal environmental gradients being less striking than those among latitudes (Briggs 2007, but see Keeling et al. 2010), strong longitudinal size gradients are also evident (Figs. 2 \& 3). However, relative to these body size differences, patterns of species richness among ocean basins are well documented. For example, clear differences exist between the North Atlantic and North Pacific (Briggs 2008) and across tropical longitudes. Marine species diversity reaches maxima in the Indo-Pacific (Ormond \& Roberts 1997, Bellwood \& Hughes 2001) and in the West Atlantic Caribbean (Briggs 2007), and declines radially from these maxima (Briggs 2005, 2007). The high diversity of these tropical areas may be influenced by the area of shallow water suitable for small, coraldependent species (Bellwood \& Hughes 2001), the location of regional centres of evolutionary radiation (Briggs 2007), and/or other factors (Ormond \& Roberts 1997). In the context of the current analyses, average fish species sizes approach their minima in LMEs within and adjacent to these diversity maxima (Figs. 2 $\& 3$, Table 1). Given these patterns, future analyses of variations among species size distributions will need to consider both latitudinal and longitudinal influences.
The among-LME differences in mean fish lengths we report are robust to concerns of incomplete sampling within some LMEs obscuring true species size distributions. Sustained sampling through time tends to accumulate smaller species and, consequently, thoroughly inventoried assemblages may exhibit smaller average sizes (Blackburn \& Gaston 1994). However, global analyses of the degree of completeness of a temporal and georeferenced marine fish taxonomic inventory show high diversity tropical areas to be among the least thoroughly sampled (Mora et al. 2008), and new marine fish species are being discovered annually in tropical locations that possess the highest species diversity (Briggs 2005). Thus, if anything, the differences in geometric mean fish lengths between tropical and extra-tropical LMEs we report (Figs. 2 \& 3) are likely to be conservative. The absence of relative abundance data for species could limit our comparisons of size structure among global LMEs. However, published relationships of species body sizes, species relative abundances, and species richness within assemblages suggests otherwise (Hubbell 2001, Pope et al. 2009, Buckley \& Jetz 2010). In general, both terrestrial and aquatic low diversity ecosystems tend to have abundance distributions dominated by relatively few species (Hubbell 2001, Buckley \& Jetz 2010), and large-bodied species tend to dominate local resources within ecosystems (Brown \& Maurer 1986). One consequence of this pattern is that LMEs characterized by low diversity fish assemblages that also contain higher proportions of large-bodied species are likely to be more vulnerable to the destabilizing effects of size-selective harvesting. 


\section{Is body size a missing metric in marine ecosystem functioning?}

The potential for organism size (or other factors) to be an unrecognized cause of reported positive relationships between species richness and ecosystem functioning was recognized by Huston (1997), who demonstrated that larger average plant height in high diversity experiments represented a potential 'hidden treatment'. The strong negative correlation between species richness and mean fish lengths among the global LMEs we examined (Fig. 4) suggests that an analogous 'missing metric' may mediate previously reported relationships between species richness and multiple measures of ecosystem functioning (Worm et al. 2006). This hypothesis challenges the assumed primacy of species richness alone as a regulator of ecosystem function in exploited assemblages and reinforces the call for a reexamination of the factors underlying relationships between biodiversity and ecosystem functioning (Hillebrand \& Matthiessen 2009).

Size-based indicators of marine ecosystem function have been increasingly employed (e.g. Jennings 2005, Shin et al. 2005) and body sizes have declined in a consistent direction within both high and low diversity assemblages in response to fishing pressure (e.g. Bianchi et al. 2000, Choi et al. 2005, Reynolds et al. 2005, Shackell et al. 2010). For example, in Northwest Atlantic LMEs, where high latitude fisheries collapsed (Frank et al. 2007), fish body masses exhibited monotonic declines of $\sim 50 \%$ (Fisher et al. in press) during a period when species richness oscillated interannually without trend (Fisher et al. 2008). Ongoing declines in total biomass and species turnover times driven by declines in large-bodied individuals are characteristic of contemporary North Sea fish assemblages (Jennings \& Blanchard 2004), where species richness has increased monotonically by $\sim 50 \%$ (Hiddink \& ter Hofstede 2008). Even in the Western Scotian Shelf ecosystem, where top predator biomass and species richness have remained virtually constant, a trophic cascade and the associated impacts on ecosystem structure have been attributed to declines in the average species body size of $\sim 50 \%$ (Shackell et al. 2010). Finally, based on marine trawl survey data combined from 19 ecosystems, a decline in total biomass of $32 \%$ was reported (Worm et al. 2009). However, within this aggregate, changes in fish biomass were strongly related to maximum sizes per species, as large-bodied demersal species (those with maximum lengths $\geq 90 \mathrm{~cm}$ ) declined by $56 \%$, medium demersals (30 to $90 \mathrm{~cm})$ declined by $8 \%$, and small demersals $(\leq 30 \mathrm{~cm})$ declined by $1 \%$; invertebrate $(23 \%)$ and pelagic biomass $(143 \%)$ both increased (Worm et al. 2009). These, and our findings, suggest that reductions in average body size, whether resulting from environmental (Choi et al. 2005, Shackell et al. 2010) or sizeselective fishing (Bianchi et al. 2000, Shin et al. 2005, Worm et al. 2009) may impact ecosystem functioning and/or stability more rapidly and more profoundly than, or even in the absence of, declines in species richness.

Consistent with the patterns previously reported for other species assemblages (Blackburn \& Gaston 1994), the global body size distribution of marine fishes is significantly positively skewed towards small-bodied species (Olden et al. 2007). However, North Atlantic LMEs show anomalous patterns (Fig. 5) that parallel increasing skewness towards large species with increasing latitude, as documented for birds (Olson et al. 2009), Arctic fishes (Lindsey 1966), and North American freshwater fish assemblages (McDowall 1994, Knouft 2004). These skewness patterns (Fig. 5) may also have important functional consequences for fish assemblages exposed to large size-biased exploitation. Indeed, the interaction between this skewness and species richness (Fig. 4) suggests a double jeopardy for North Atlantic fish assemblages, given that these historically low diversity ecosystems were also dominated by large-bodied species that are most vulnerable to extinction (Reynolds et al. 2005, Olden et al. 2007) and subjected to fisheries managed via minimum size limits (Shin et al. 2005, Pope et al. 2009).

More than a century ago, 6 of the 8 LMEs we studied, having geometric mean species lengths $>50 \mathrm{~cm}$ (Nos. 9 , 21, 22, 24, 59, 60, and also 20; Figs. 2 \& 3, Table 1), were identified by Johnstone (1908, p. 201-202) as the main foci of commercial fisheries. This he attributed to their dominance by large-bodied species. Many of these same LMEs experienced dramatic and sudden collapses of their large-bodied top predators in the late 1980s and early 1990s in response to overfishing and environmental change, both of which negatively affected average body size and ecosystem functioning (Sherman \& Skjoldal 2002, Choi et al. 2005, Leggett \& Frank 2008) but had minimal impact on species diversity (Bianchi et al. 2000, Fisher et al. 2008). Apparently, the same features of North Atlantic marine ecosystems that historically attracted fisheries - a low diversity of species attaining large body sizes (Johnstone 1908) made those ecosystems inherently more susceptible to overexploitation and collapse.

\section{Fisheries stability in the North Atlantic and North Pacific}

In a biodiversity-ecosystem functioning context, 2 contrasting positions have recently been offered to explain the anomalous declines in North Atlantic fish- 
ery yields relative to those in the North Pacific (Essington et al. 2006). Based on positive correlations between species richness and ecosystem services at a global scale (Worm et al. 2006), Briggs (2008) inferred that that the multiple reported declines in North Atlantic ecosystem functioning were due to historically lower species richness in the North Atlantic relative to the North Pacific. Briggs (2008) further suggested that introductions of North Pacific species into the North Atlantic to bolster species richness there would prevent additional degradation of North Atlantic ecosystems. Courtenay et al. (2009) rejected this proposition, arguing that there was little evidence of a direct link between species richness and ecosystem resilience. They argued that excessive and uncontrolled fishing pressure was the primary reason for the fishery failures in the North Atlantic in contrast to the better managed North Pacific.

However, as our analyses show, the distribution of body sizes among species also differs strikingly between these 2 ocean basins (Figs. 2, 3, 5 to 8), even within ecosystems characterized by similar or identical species richness (Fig. 9). North Atlantic ecosystems have both larger mean fish lengths and size distributions skewed towards dominance by large species. These patterns suggest that a differential sensitivity to the influence of size-selective fisheries resulting from the historical differences in body size distributions in the 2 regions may explain the anomalous declines in top predator catch rates in North Atlantic LMEs relative to those in the North Pacific (Essington et al. 2006).

The results of our reanalysis of the temporal data of Essington et al. (2006) (Fig. 10) are also consistent with the hypothesis that body size is important to ecosystem functioning. Given the strong negative relationship between body size and species richness (Fig. 4), the reality that body size has twice the power of species richness in explaining geographical variation in the yield of top predators (Fig. 10), and the widely reported declines in body size that have occurred in many ecosystem studies (Bianchi et al. 2000, Shin et al. 2005), we conclude that body size may play an important mechanistic role in determining the relationship between species richness and ecosystem functioning. The magnitude of differences in, and the geographic patterns of, body size variations among global LMEs may constitute a missing metric in the differential stability of LMEs when subjected to exploitation. Moreover, our demonstration that fish size structure is more sensitive than species richness to overexploitation argues strongly for the importance of a renewed focus on restoring and maintaining key species traits in size-structured assemblages.
Acknowledgements. We thank the researchers behind the Large Marine Ecosystems of the World Project, the Sea Around Us Project, and Fishbase.org for sharing marine biodiversity data online. Drs. B. Petrie, N. Shackell and the reviewers and editors provided many helpful comments on earlier versions. Funding for this research was provided by NSERC Discovery grants to K.T.F. and W.C.L., and the Canadian Department of Fisheries and Oceans.

\section{LITERATURE CITED}

Baum JK, Worm B (2009) Cascading top-down effects of changing oceanic predator abundances. J Anim Ecol 78: 699-714

Belkin IM (2009) Rapid warming of large marine ecosystems. Prog Oceanogr 81:207-213

Bellwood DR, Hughes TP (2001) Regional-scale assembly rules and biodiversity of coral reefs. Science 292: 1532-1534

Berkeley SA, Hixon MA, Larson RJ, Love MS (2004) Fisheries sustainability via protection of age structure and spatial distribution of fish populations. Fisheries 29:23-32

> Bianchi G, Gislason H, Graham K, Hill L and others (2000) Impact of fishing on size composition and diversity of demersal fish communities. ICES J Mar Sci 57:558-571

Blackburn TM, Gaston KJ (1994) Animal body size distributions: patterns, mechanisms and implications. Trends Ecol Evol 9:471-474

Blackburn TM, Gaston KJ, Loder N (1999) Geographic gradients in body size: a clarification of Bergmann's rule. Divers Distrib 5:165-174

> Briggs JC (2005) The marine East Indies: diversity and speciation. J Biogeogr 32:1517-1522

> Briggs JC (2007) Marine longitudinal biodiversity: causes and conservation. Divers Distrib 13:544-555

Briggs JC (2008) The North Atlantic Ocean: need for proactive management. Fisheries 33:180-185

> Brown JH, Maurer BA (1986) Body size, ecological dominance and Cope's rule. Nature 324:248-250

Buckley LB, Jetz W (2010) Lizard community structure along environmental gradients. J Anim Ecol 79:358-365

Choi JS, Frank KT, Petrie BD, Leggett WC (2005) Integrated assessment of a large marine ecosystem: a case study of the devolution of the eastern Scotian Shelf, Canada. Oceanogr Mar Biol Annu Rev 43:47-67

Courtenay WR Jr, Collette BB, Essington TE, Hilborn R and others (2009) Risks of introductions of marine fishes: reply to Briggs. Fisheries 34:181-186

- Essington TE, Beaudreau AH, Wiedenmann J (2006) Fishing through marine food webs. Proc Natl Acad Sci USA 103: 3171-3175

Fisher JAD, Frank KT, Petrie B, Leggett WC, Shackell NL (2008) Temporal dynamics within a contemporary latitudinal diversity gradient. Ecol Lett 11:883-897

Fisher JAD, Frank KT, Leggett WC (in press) Breaking Bergmann's rule: truncation of Northwest Atlantic marine fish body sizes. Ecology

Frank KT, Petrie B, Shackell NL (2007) The ups and downs of trophic control in continental shelf ecosystems. Trends Ecol Evol 22:236-242

Froese R, Pauly D (eds) (2008) FishBase. Available at www.fishbase.org

Giller PS, Hillebrand H, Berninger UG, Gessner MO and others (2004) Biodiversity effects on ecosystem functioning: emerging issues and their experimental test in aquatic environments. Oikos 104:423-436

Hiddink JG, ter Hofstede R (2008) Climate induced increases 
in species richness of marine fishes. Glob Change Biol 14: $453-460$

Hildrew AG, Raffaelli DG, Edmonds-Brown R (eds) (2007) Body size: the structure and function of aquatic ecosystems. Cambridge University Press, Cambridge

Hillebrand H, Matthiessen B (2009) Biodiversity in a complex world: consolidation and progress in functional biodiversity research. Ecol Lett 12:1405-1419

Hubbell SP (2001) The unified neutral theory of biodiversity and biogeography. Princeton University Press, Princeton, NJ

Huston MA (1997) Hidden treatments in ecological experiments: re-evaluating the ecosystem function of biodiversity. Oecologia 110:449-460

Huston MA, Wolverton S (2009) The global distribution of net primary production: resolving the paradox. Ecol Monogr 79:343-377

Hutchings JA (2002) Life histories of fish. In: Hart PJB, Reynolds JD (eds) Handbook of fish biology and fisheries, Vol 1. Blackwell Publishing, Malden, MA, p 149-174

Jennings $S$ (2005) Indicators to support an ecosystem approach to fisheries. Fish Fish 6:212-232

> Jennings S, Blanchard JL (2004) Fish abundance with no fishing: predictions based on macroecological theory. J Anim Ecol 73:632-642

> Jennings S, Pinnegar JK, Polunin NVC, Boon T (2001) Weak cross-species relationships between body size and trophic level belie powerful size-based trophic structuring in fish communities. J Anim Ecol 70:934-944

Johnstone J (1908) Conditions of life in the sea. Cambridge University Press, Cambridge

Keeling RF, Körtzinger A, Gruber N (2010) Ocean deoxygenation in a warming world. Annu Rev Mar Sci 2: 199-229

Knouft JH (2004) Latitudinal variation in the shape of the species body size distribution: an analysis using freshwater fishes. Oecologia 139:408-417

Leggett WC, Carscadden JE (1978) Latitudinal variation in reproductive characteristics of American shad (Alosa sapidissima): evidence for population specific life history strategies in fish. J Fish Res Board Can 35:1469-1478

Leggett WC, Frank KT (2008) Paradigms in fisheries oceanography. Oceanogr Mar Biol Annu Rev 46:331-363

> Lindsey CC (1966) Body sizes of poikilotherm vertebrates at different latitudes. Evolution 20:456-465

- Loreau M, Naeem S, Inchausti P, Bengtsson J and others (2001) Biodiversity and ecosystem functioning: current knowledge and future challenges. Science 294:804-808

Macpherson E, Duarte CM (1994) Patterns in species richness, size, and latitudinal range of East Atlantic fishes. Ecography 17:242-248

McCann K (2007) Protecting biostructure. Nature 446:29

McDowall RM (1994) On size and growth in freshwater fish. Ecol Freshw Fish 3:67-79

Millien V, Lyons SK, Olson L, Smith FA, Wilson AB, Yom-Tov Y (2006) Ecotypic variation in the context of global climate change: revisiting the rules. Ecol Lett 9:853-869

Mora C, Tittensor DP, Myers RA (2008) The completeness of taxonomic inventories for describing the global diversity and distribution of marine fishes. Proc R Soc Lond B 275: 149-155

Naeem S, Wright JP (2003) Disentangling biodiversity effects on ecosystem functioning: deriving solutions to a seemingly insurmountable problem. Ecol Lett 6:567-579

Norberg J (2004) Biodiversity and ecosystem functioning: a complex adaptive systems approach. Limnol Oceanogr 49: 1269-1277

Olden JD, Poff NL, Douglas MR, Douglas ME, Fausch KD
(2004) Ecological and evolutionary consequences of biotic homogenization. Trends Ecol Evol 19:18-24

Olden JD, Hogan ZS, Vander Zanden MJ (2007) Small fish, big fish, red fish, blue fish: size-biased extinction risk of the world's freshwater and marine fishes. Glob Ecol Biogeogr 16:694-701

Olson VA, Davies RG, Orme CDL, Thomas GH and others (2009) Global biogeography and ecology of body size in birds. Ecol Lett 12:249-259

Ormond RFG, Roberts C M. (1997) The biodiversity of coral reef fishes. In: Ormond RFG, Gage JD, Angel MV (eds) Marine biodiversity: patterns and processes. Cambridge University Press, Cambridge, p 216-257

Palumbi SR, Sandifer PA, Allan JD, Beck MW and others (2009) Managing for ocean biodiversity to sustain marine ecosystem services. Front Ecol Environ 7:204-211

Pauly D (1998) Tropical fishes: patterns and propensities. J Fish Biol 53(Suppl A):1-17

Planque B, Fromentin JM, Cury P, Drinkwater KF, Jennings S, Perry RI, Kifani S (2010) How does fishing alter marine populations and ecosystems sensitivity to climate? J Mar Syst 79:403-417

Pope JG, Falk-Pedersen J, Jennings S, Rice JC, Gislason H, Daan N (2009) Honey, I cooled the cods: modelling the effect of temperature on the structure of boreal/Arctic fish ecosystems. Deep-Sea Res II 56:2097-2107

Reiss J, Bridle JR, Montoya JM, Woodward G (2009) Emerging horizons in biodiversity and ecosystem functioning research. Trends Ecol Evol 24:505-514

Reynolds JD, Dulvy NK, Goodwin NB, Hutchings JA (2005) Biology of extinction risk in marine fishes. Proc Biol Sci 272:2337-2344

Roy K, Jablonski D, Martien KK (2000) Invariant size-frequency distributions along a latitudinal gradient in marine bivalves. Proc Natl Acad Sci USA 97:13150-13155

SAS Institute (2000) JMP® statistics and graphics guide, version 4. SAS Institute, Cary, NC

Schaffer WM, Elson PF (1975) The adaptive significance of variations in life history among local populations of Atlantic salmon in North America. Ecology 56:577-590

Sea Around Us Project (2008) A global database on marine fisheries and ecosystems. Available at www.seaaroundus. org

Shackell NL, Frank KT, Fisher JAD, Petrie B, Leggett WC (2010) Decline in top predator body size and changing climate alter trophic structure in an oceanic ecosystem. Proc Biol Sci 277:1353-1360

Sherman K, Skjoldal HR (eds) (2002) Large marine ecosystems of the North Atlantic: changing states and sustainability. Elsevier Science, Amsterdam

Sherman K, Belkin IM, Friedland KD, O'Reilly J, Hyde K (2009) Accelerated warming and emergent trends in fisheries biomass yields of the world's large marine ecosystems. Ambio 38:215-224

Shin YJ, Rochet MJ, Jennings S, Field JG, Gislason H (2005) Using size-based indicators to evaluate the ecosystem effects of fishing. ICES J Mar Sci 62:384-396

Solan M, Cardinale BJ, Downing AL, Engelhardt KAM, Ruesink JL, Srivastava DS (2004) Extinction and ecosystem function in the marine benthos. Science 306: 1177-1180

Watt C, Mitchell S, Salewski V (2010) Bergmann's rule; a concept cluster? Oikos 119:89-100

- Worm B, Barbier EB, Beaumont N, Duffy JE and others (2006) Impacts of biodiversity loss on ocean ecosystem services. Science 314:787-790

- Worm B, Hilborn R, Baum JK, Branch TA and others (2009) Rebuilding global fisheries. Science 325:578-585 